\title{
Cortisol-Producing Adrenal Cortex Adenoma
}

National Cancer Institute

\section{Source}

National Cancer Institute. Cortisol-Producing Adrenal Cortex Adenoma. NCI Thesaurus.

Code C48449.

An adenoma of the adrenal cortex that produces cortisol. It may be associated with Cushing syndrome. Clinical presentation includes weight gain, round face, easy bruising, muscle weakness, emotional changes, hirsutism, and hypertension. 